\title{
Promosi Kampus Berbasis Augmented Reality
}

\author{
Mugni Santoso $^{1^{*}}$, Cipta Riang Sari ${ }^{2}$, Syarli Jalal ${ }^{3}$ \\ 1,2,3 Universitas Al Asyariah Mandar, Indonesia \\ ${ }^{1}$ 404mugi@gmail.com \\ * corresponding author
}

\begin{tabular}{|c|c|}
\hline ABSTRACT & Article Info \\
\hline $\begin{array}{l}\text { In line with Industry 4.0, the author makes an augmented reality application as a promotional } \\
\text { medium to convey campus information to the public, especially prospective students and students } \\
\text { from Al Asyariah Mandar University. By using augmented reality technology, users can interact } \\
\text { in digital (virtual) form. So AR is the proper application to make campus promotions more } \\
\text { interesting. Analytical techniques are applied to design and create augmented reality-based } \\
\text { campus promotion applications using qualitative analysis methods that prioritize the user } \\
\text { interface, user experience, animation and } 3 d \text { menu design. This application is made using the } \\
\text { marked base tracking method. This augmented reality-based campus promotion application can } \\
\text { display an AR camera system and render } 3 D \text { objects of hall buildings, computer laboratories, } \\
\text { mosques, classrooms and rectorates well. This augmented reality-based campus promotion } \\
\text { application works well on Android systems. We hope that this application can be further } \\
\text { developed so that it can be used on several platforms, not only on Android. }\end{array}$ & $\begin{array}{r}\text { Article history } \\
\text { Received: Aug. } 29^{\text {th }}, 2021 \\
\text { Revised: Nov. } 27^{\text {th }}, 2021 \\
\text { Accepted: Nov. } 30^{\text {th }}, 2021 \\
\\
\text { Keywords } \\
\text { Promotion, } \\
\text { AR, } \\
3 D, \\
\text { Unity Marker. }\end{array}$ \\
\hline ABSTRAK & \\
\hline $\begin{array}{l}\text { Sejalan dengan Industri 4.0, penulis membuat aplikasi augmented reality sebagai media promosi } \\
\text { untuk menyampaikan informasi kampus kepada masyarakat khususnya calon peserta didik dan } \\
\text { mahasiswa. dari Universitas Al Asyariah Mandar. Dengan menggunakan teknologi augmented } \\
\text { reality, pengguna dapat melakukan interaksi dalam bentuk digital (virtual). Jadi AR adalah } \\
\text { aplikasi yang tepat untuk membuat promosi kampus menjadi lebih menarik. Teknik analisis } \\
\text { diterapkan untuk merancang dan membuat aplikasi promosi kampus berbasis augmented reality } \\
\text { menggunakan metode analisis kualitatif yang mengutamakan antarmuka pengguna, pengalaman } \\
\text { pengguna, animasi dan desain menu 3d. Pembuatan aplikasi ini menggunakan metode marked } \\
\text { base tracking. Aplikasi promosi kampus berbasis augmented reality ini dapat menampilkan } \\
\text { sistem kamera AR dan merender objek 3D bangunan aula, laboratorium komputer, masjid, } \\
\text { Gedung kelas dan rektorat dengan baik. Aplikasi promosi kampus berbasis augmented reality ini } \\
\text { bekerja dengan baik di sistem Android. Kami berharap aplikasi ini dapat dikembangkan lebih } \\
\text { lanjut sehingga dapat digunakan di beberapa platform, tidak hanya pada Android. }\end{array}$ & \\
\hline
\end{tabular}

\section{PENDAHULUAN}

Universitas Al Asyariah Mandar berdiri ketika banyak lulusan SMA dari wilayah Polewali Mandar ingin melanjutkan studi ke universitas tersebut, namun terkendala oleh jarak, transportasi dan biaya hidup. Selama kurun waktu 2004-2020 Universitas A1 Asyariah Mandar mengalami kemajuan yang sangat pesat terbukti dengan bertambahnya jumlah mahasiswa, sarana prasarana dan juga tenaga pengajar, Universitas Al Asyariah Mandar telah memberikan pengaruh positif terhadap perannya dalam pendidikan tinggi, agama melalui perkembangan agamanya. dan melestarikan budaya lokal di Kabupaten Polewali Mandar. 
Pengguna Android khususnya di lingkungan kampus Universitas Al Asyariah Mandar sangat melimpah baik dari kalangan mahasiswa maupun dosen, sedangkan pembaca media cetak sebagai alat komunikasi tradisional semakin langka. media digital diperbarui setiap detik. dan dapat diakses kapan saja dan dimana saja selama pengguna Android memiliki akses internet.

Teknologi informasi yang dibantu oleh pertumbuhan internet telah menggeser preferensi membaca masyarakat dari kegiatan membaca pada media cetak. Hal ini dibuktikan dengan kebiasaan masyarakat yang hanya fokus pada judul bacaan tanpa melihat isinya. Membaca membutuhkan keterampilan konsentrasi yang lebih tinggi daripada menonton TV atau membuka media sosial, yang membuat kegiatan membaca terkesan lebih sulit dan berat. Sementara itu, jejaring sosial memberikan hal-hal yang lebih menarik untuk meningkatkan minat baca masyarakat.

Karena kurangnya minat masyarakat terhadap media cetak, penulis berpendapat bahwa diperlukan penelitian tentang praktik yang baik dalam mempromosikan kampus di media digital sekaligus menyambut Industri 4.0. diperlukan cara yang tepat untuk menyampaikan informasi kampus kepada masyarakat, khususnya calon mahasiswa dan mahasiswa Universitas Al Asyariah Mandar.

Dengan menggunakan teknologi augmented reality (AR) sebagai media informasi yang lebih menarik, lingkungan sekitar kita dapat melakukan interaksi dalam bentuk digital (virtual) (Firdaus, dkk, 2018). Informasi tentang objek dan lingkungan dapat ditambahkan ke sistem augmented reality, yang kemudian dapat ditampilkan di layar ponsel secara real time seolah-olah informasi itu nyata (Kurniawan, $\mathrm{dkk}$, 2020). Melalui augmented reality, promosi kampus dapat dilakukan dengan lebih baik dan menarik. (Zuono, dkk, 2019). Ini menjadikan AR sebagai aplikasi yang tepat untuk membuat promosi kampus yang lebih menarik.

Berdasarkan uraian dan permasalahan di atas, penulis tertarik untuk merancang dan membangun aplikasi berbasis android yang berjudul "Promosi Kampus Berbasis Augmented Reality” sehingga dapat digunakan untuk melakukan pengenalan gedung gedung kampus dalam bentuk 3D.

\section{KERANGKA TEORI}

\section{a. Promosi}

Promosi merupakan bagian dari rencana komunikasi karena produk yang dibawa ke pasar memerlukan promosi. Sedangkan promosi memerlukan strategi perencanaan komunikasi. Dalam kegiatan promosi seringkali muncul anggapan yang salah bahwa biaya promosi dianggap boros, sedangkan biaya promosi yang dikeluarkan harus dianggap sebagai investasi (Reftari et al., 2018).

\section{b. Augmented Reality}

Augmented Reality (AR) adalah rendering realtime langsung atau tidak langsung dari objek fisik dengan menambahkan objek ke dunia maya untuk membuat informasi tambahan tentang objek yang ada. Augmented reality menggabungkan objek nyata dan yang ada.

Objek virtual hanya menambah, bukan mengganti, objek nyata, sedangkan tujuan dari augmented reality adalah menyederhanakan objek nyata dengan membuat objek virtual sehingga informasi tidak hanya tersedia untuk pengguna secara langsung (user interface), tetapi juga untuk semua pengguna yang tidak berhubungan langsung dengan user interface objek nyata, seperti streaming video langsung. Perangkat utama untuk augmented reality adalah monitor, perangkat input, Marker, dan komputer (Zain, 2006).

\section{c. Unity 3D}

Unity 3D adalah mesin game cross-platform. Unity dapat digunakan untuk membuat game yang bisa digunakan di komputer, smartphone Android, iPhone, Playstation, bahkan XBOX. Unity adalah alat terintegrasi untuk membuat game, membangun 
arsitektur, dan simulasi. Unity bisa digunakan untuk game PC dan game online. Untuk game online, diperlukan plug-in yaitu Unity Web Player, dan Flash Player di browser. Unity tidak dirancang untuk proses pemodelan atau desain, karena Unity bukanlah alat desain. Jika Anda ingin mendesain, silakan gunakan editor 3D lain, seperti $3 \mathrm{dsmax}$ atau Blender. Unity dapat melakukan banyak hal, termasuk fungsi audio reverb zone, efek partikel, dan skybox yang menambahkan langit. Fungsi skrip yang disediakan mendukung 3 bahasa pemrograman, JavaScript, C\# dan Boo. Fleksibel dan mudah untuk memindahkan, memutar, dan menskalakan objek hanyalah satu baris kode. Hal yang sama berlaku untuk menyalin, menghapus, dan mengubah atribut. Variabel atribut visual yang ditentukan oleh skrip ditampilkan di editor. Itu dapat dipindahkan, diseret dan dijatuhkan, dan warnanya dapat dipilih dengan pemilih warna. Berbasis .NET. Ini berarti bahwa program berjalan pada platform .NET open source Mono.

Unity 3D adalah perangkat lunak/alat terintegrasi untuk membuat bentuk objek 3D dalam video game atau lingkungan interaktif lainnya, seperti visualisasi arsitektur real time atau animasi 3D. Lingkungan pengembangan Unity 3D dapat berjalan di Microsoft Windows dan Mac Os X. Aplikasi yang dibuat oleh Unity 3D dapat berjalan di Windows, Mac, Xbox 360, Playstation 3, Wii, iPad, iPhone dan Android. Android adalah sebuah platform berbasis sistem operasi Linux. Dirancang untuk perangkat seluler (Bagus \& Mahendra, 2016).

\section{METODE PENELITIAN}

\section{Bahan Penelitian}

Bahan yang digunakan dalam penelitian ini adalah data ukuran gedung - gedung kampus seperti gedung rektorat, auditorium, masjid, laboratorium dan gedung kelas. Juga informasi berupa sarana dan prasarana kampus. Dari data inilah akan dihasilkan metode yang akan digunakan dalam penelitian ini untuk membuat aplikasi Augmented Reality.

\section{Kerangka sistem}

Perancangan sistem adalah suatu struktur dimana elemen yang terpisah diatur dalam kesatuan yang utuh dan bermanfaat. Berikut ini merupakan kerangka sistem aplikasi Promosi Kampus Berbasis Augmented Reality yang akan dibuat untuk mencapai tujuan yang diinginkan.

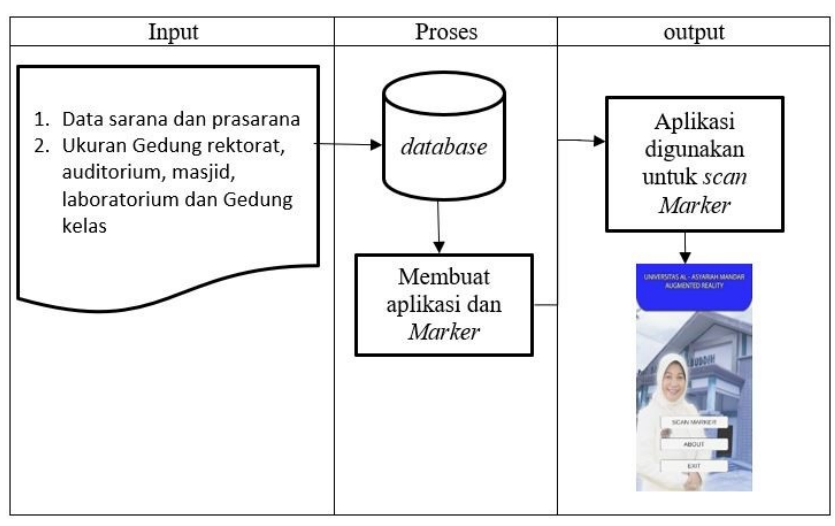

Gambar 1. Kerangka Sistem

\section{Tahapan Penelitian}

a. Pada tahap pertama yang akan dilakukan adalah bagaimana menentukan suatu masalah yang kemudian menjadi topik penelitian. Maka penulis mengangkat topik penelitian dengan judul "Promosi Kampus Berbasis Augmented Reality".

b. Kemudian mencari referensi sebagai acuan untuk mendukung penelitian berupa jurnal, buku, skripsi penelitian dan referensi lain yang dapat dijadikan sebagai referensi.

c. Setelah melakukan perancangan sistem yang menjadi objek penelitian.

d. Mengumpulkan data yang telah diperoleh dari progress yang telah dilakukan seperti pengamatan langsung di lokasi penelitian.

e. Selanjutnya adalah pengujian sistem yang telah dirancang.

f. Terakhir dilaksanakan penyelesaian rancangan sistem yang telah dirancang sebelumnya. 


\section{Teknik Pengumpulan Data}

a. Studi Pustaka

Studi pustaka merupakan teknik pengumpulan data yang dilakukan dengan cara mengumpulkan data melalui jurnal penelitian yang telah ada dan hasil karya tulis lainnya tentang Media Pembelajaran Berbasis Augmented Reality.

b. Teknik Observasi

Observasi merupakan salah satu prosedur kategorisasi informasi, dimana para ahli menyebutkan fakta-fakta yang dapat diamati secara langsung dari objek yang diteliti untuk mempelajari lebih lanjut tentang proses yang dilakukan. Prosedur dilakukan langsung di tempat, dan data diperoleh dengan mengirimkan fakta objektif langsung ke tempat yang ditentukan oleh eksplorasi yang dilakukan.

c. Wawancara

Melakukan wawancara kepada pihak-pihak terkait agar dapat menggali informasi yang lebih detail terhadap objek bangunan dan informasi yang akan disematkan.

\section{Teknik Analisis Data}

Data yang dikumpulkan melalui penelitian kepustakaan, observasi, dan wawancara kemudian harus diklasifikasikan dan disortir, dan kemudian dimasukkan ke dalam program perangkat lunak untuk dianalisis. Teknologi analitik terapan dapat menggunakan metode kualitatif untuk dengan mudah merancang dan membangun aplikasi promosi kampus berbasis augmented reality, di mana antarmuka pengguna $3 \mathrm{D}$, pengalaman pengguna, animasi, dan desain menu diprioritaskan. Saat membuat aplikasi ini, metode pelacakan penanda dasar akan digunakan.

\section{HASIL DAN PEMBAHASAN}

\section{a. Hasil Pembuatan Brosur dan Marker}

Brosur yang dibuat menggunakan informasi peneriman mahasiswa baru, beberapa informasi kampus, marker berupa gambar objek gedung dan kode QR untuk mengunduh aplikasi.

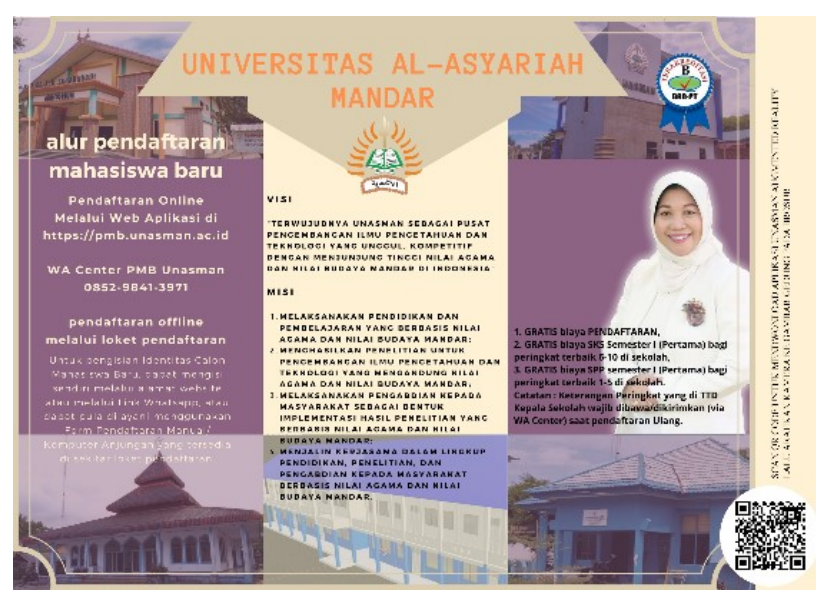

Gambar 2. Desain Brosur

Pengambilan gambar Marker juga menggunakan aplikasi photoshop dengan memotong gambar gedung pada brosur dengan skala 1:1 yang selanjutnya akan disimpan dengan format jpg, yakni format gambar yang dapat di input ke dalam database Vuforia.

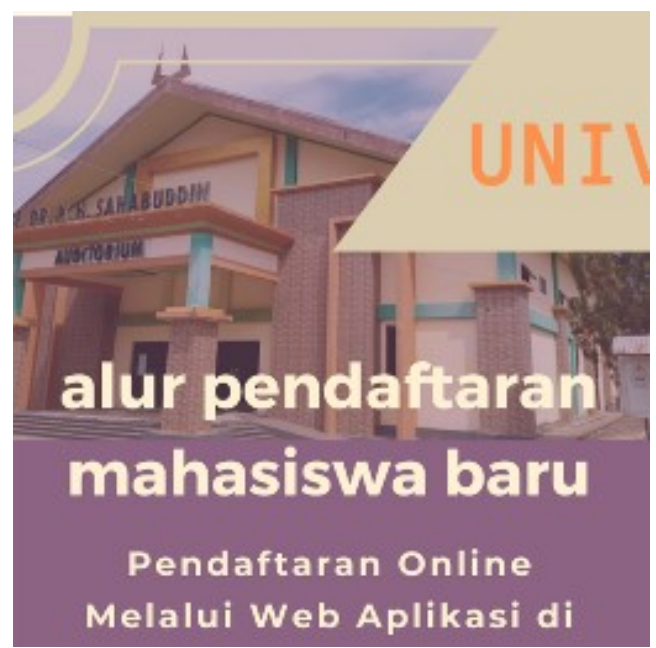

Gambar 2. Desain Marker

\section{b. Hasil Pembuatan Database}

Vuforia adalah database yang menyimpan marker yang telah dibuat agar dapat dikenali saat 
dipindai dengan kamera AR. Vuforia akan mencetak tag yang telah diunggah ke database dan skor akan muncul di tabel tag sebagai bintang. Semakin tinggi nilai yang diperoleh marker, semakin mudah bagi kamera AR untuk mengenali marker tersebut. Nilai yang didapat antara 1 dan 5 bintang. Ada juga license key yang diaktifkan terlebih dahulu di database ini agar kamera AR yang digunakan di Unity bisa diaktifkan.

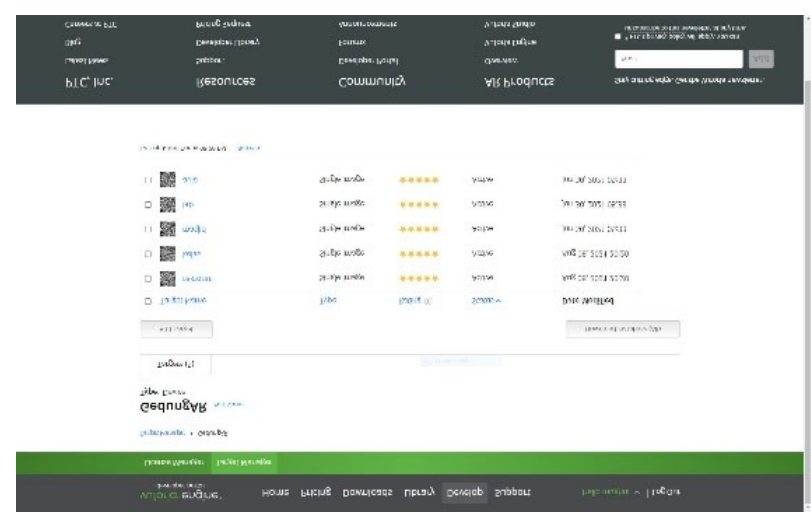

Gambar 3. Pembuatan Database

\section{c. Hasil Pembuatan Objek 3D}

Objek 3D dibuat menggunakan Blender software. Template objek 3D akan di-import ke dalam blender software kemudian di-eksport dengan format fbx. Format file yang disediakan blender mendukung untuk kemudian digunakan pada Unity.

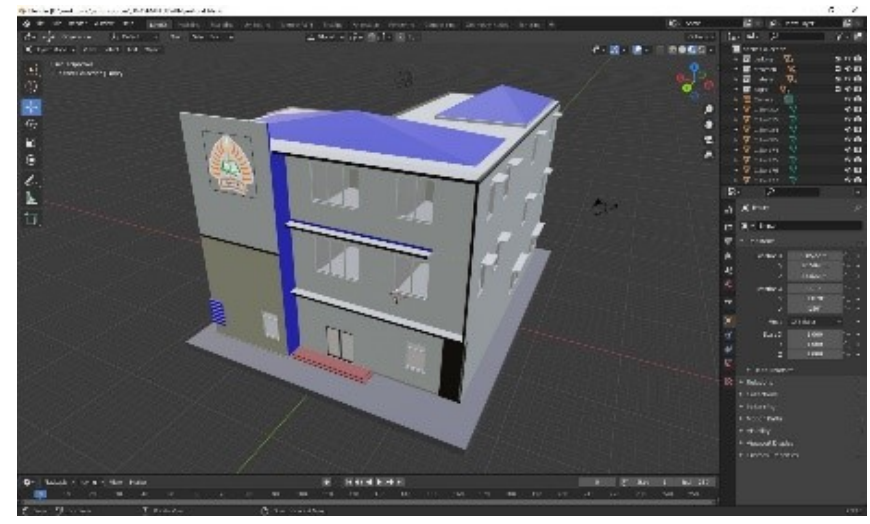

Gambar 4. Aplikasi Blender

\section{d. Penyatuan Objek dan Marker}

Selanjutnya objek dan marker akan disatukan dalam satu scene agar ketika marker dipindai oleh AR kamera objek yang sudah digabungkan ke dalam scene dapat ditampilkan. Objek yang disatukan dengan marker berupa 3D desain dan audio file.

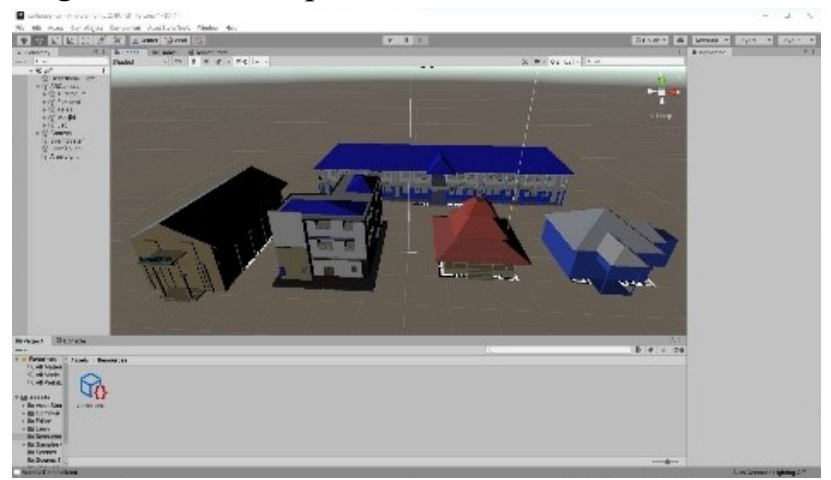

Gambar 5. Aplikasi Unity 3D

\section{e. Hasil Tampilan Antarmuka Aplikasi}

Ketika pertama kali menjalankan program maka tampilan yang muncul ialah halaman home screen yang berisi menu scan marker, about dan exit. Saat menekan tombol scan marker maka akan muncul tampilan kamera yang jika diarahkan ke marker akan memunculkan objek 3D diatas marker

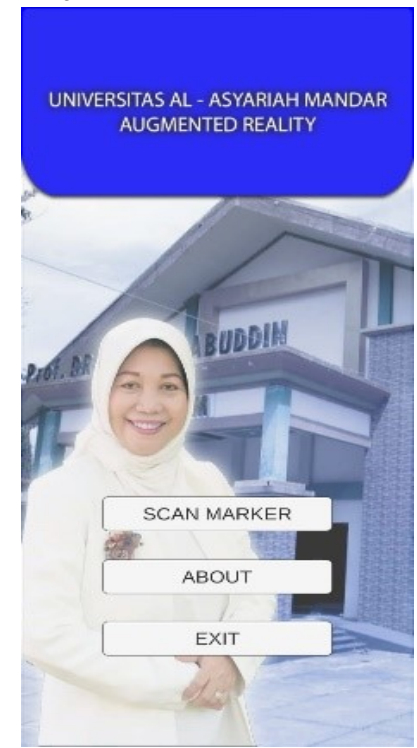

Gambar 6. Tampilan aplikasi

\section{f. Pengujian Aplikasi}


Berhasil diuji pada beberapa versi Android untuk menentukan apakah program dapat berjalan pada beberapa versi Android pada smartphone yang berbeda. Spesifikasi Android minimum agar aplikasi berfungsi dengan baik adalah Android versi 8, dengan RAM 3GB dan kamera 13 megapiksel. Sependapat dengan itu Kurniawan, dkk (2020) menjelaskan bahwa dengan AR tampilan promosi menjadi lebih baik dan menarik.

Selain itu, pengujian black box merupakan metode pengujian sistem program untuk mengetahui fungsionalitas program tanpa harus melihat kode dan struktur internal program. Hasil pengujian ini menemukan validitas penerapan aplikasi pada fungsi yang dimaksudkan.

\section{SIMPULAN}

Setelah melewati hasil dan pembahasan, maka diperoleh beberapa kesimpulan yang ditemukan pada penelitian ini yaitu :

1. Aplikasi Promosi Kampus Berbasis Augmented Reality ini mampu menampilkan sistem AR Camera dan menampilkan objek 3D gedung masjid kampus, auditorium, lab komputer, gedung kelas, dan rektorat

2. Aplikasi Promosi Kampus Berbasis Augmenetd Reality ini berjalan dengan baik pada sistem Android.

3. Semua fitur yang ada di dalam aplikasi promosi kampus berbasis Augmented Reality ini berfungsi dengan sangat baik.

\section{DAFTAR PUSTAKA}

Bagus, I., \& Mahendra, M. (2016). Implementasi Augmented Reality ( Ar ) Menggunakan Unity 3D Dan Vuporia Sdk. Jurnal Ilmiah ILMU KOMPUTER Universitas Udayana. promotion media at Faculty of Computer Science and Information Technology Mulawarman University. In Journal of Physics: Conference Series (Vol. 1341, No. 4, p. 042017). IOP Publishing.

Kurniawan, A. P., Octaviany, V., Putri, D. R. I., Ikhsan, B., \& Adianto, D. (2020). Android mobile application for promotion of pangandaran leading tourism in augmented reality technology. International Journal of Applied Information Technology, 4(1), 10-6.

Reftari, D. H., Suryana, A., \& Setiaman, A. (2018). Komunikasi Pemasaran Olahraga Renang. Jurnal Kajian Komunikasi, 6(2). https://doi.org/10.24198/jkk.v6i2.13221

Zain, S. B. D. dan A. (2006). Strategi Belajar Mengajar. Jakarta: PT Rineka Cipta. Syaiful Bahri Djamarah Dan Aswan Zain.

Zuono, T. T., Hatta, M., Kurniawan, C., Sugiarto, I., Anggraini, M., Purwadi, A.,\& Kertamukti, R. (2019, March). Build design introduction to university profiles using the logo with the augmented reality method. In Journal of Physics: Conference Series (Vol. 1175, No. 1, p. 012115). IOP Publishing.

Firdaus, M. B., Widians, J. A., \& Padant, J. Y. (2019, October). Augmented reality for interactive 